\title{
Pembuatan Nutrisi dan Penyuluhan Penyakit Hipertensi pada Anggota PKK Delima Jakarta Timur
}

\author{
Vivi Anggia ${ }^{*}$, Tuti Wiyati ${ }^{1}$, Nora Wulandari ${ }^{1}$ \\ ${ }^{1}$ Fakultas Farmasi dan Sains, Universitas Muhammadiyah Prof. Dr. Hamka, Jalan Delima II/IV, Perumnas \\ Klender, Jakarta Timur \\ *Email: vivi.anggia@uhamka.ac.id
}

\begin{abstract}
Abstrak
Menurut data SUDINKES DKI Jakarta tahun 2016 menunjukkan bahwa kotamadya Jakarta Timur memiliki jumlah populasi yang hipertensi lebih banyak dibandingkan dengan daerah lainnnya yaitu sebanyak 98422 orang. Konsumsi buah dan sayuran segar akan memberikan banyak manfaat bagi tubuh kita, bukan saja rasanya yang enak tapi buah dan sayur kaya akan antioksidan yang bermanfaat untuk mencegah terjadinya stres oksidatif dan bisa menjadi salah satu upaya dalam mencegah dan mengobati hipertensi. Berbagai buah dan sayuran banyak yang telah diteliti memberikan khasiat antihipertensi. Pada pengabdian masyarakat ini kami mengadakan Pelatihan pembuatan nutrisi dan penyuluhan penyakit hipertensi pada anggota PKK RT. 014 Perumnas Klender Jakarta Timur. Buah-buahan dan sayur-sayuran yang kami gunakan adalah belimbing, semangka, lemon, seledri dan mentimun.
\end{abstract}

Kata kunci: Hipertensi, nutrisi, antioksidan

\section{Abstract}

According Data of SUDINKES of Jakarta in 2016 showed that the East Jakarta had a higher population of hypertension compared to other regions, which were as many as 98422 people. Consumption of fresh fruits and vegetables provides many benefits for our body, not only it taste is good but fruit and vegetables are rich in antioxidants that are useful for preventing oxidative stress and can be an effort to prevent and treat hypertension. Various fruits and vegetables that have been studied provide antihypertensive properties. At this community service we held a training in making nutrition and counseling for hypertension in PKK members RT. 014 Perumnas Klender East Jakarta. The fruits and vegetables we use are starfruit, watermelon, lemon, celery and cucumber.

Keywords: hypertension, nutrision, antioxidant

Format Sitasi: Anggia, V., Wiyati, T. \& Wulandari, N. (2019). Pembuatan Nutrisi dan Penyuluhan Penyakit Hipertensi pada Anggota PKK Delima Jakarta Timur. Jurnal Solma, 08(1), 01-04. Doi: http://dx.doi.org/10.29405/solma.v8i1.3059

Diterima: 09 Februari 2019 | Revisi: 01 April 2019 | Dipublikasikan: 05 April 2019.

\section{PENDAHULUAN}

Hipertensi didefinisikan sebagai kondisi meningkatnya tekanan darah secara persisten. Hipertensi dapat disebabkan oleh penyebab yang spesifik (hipertensi sekunder) atau dari etiologi yang tidak diketahui (hipertensi primer atau hipertensi esensial). Seseorang dikatakan hipertensi jika memiliki tekanan darah sistolik lebih besar dari 140 
mmHg dan atau diastolik lebih besar dari $90 \mathrm{mmHg}$ pada keadaan cukup istirahat dengan pengukuran dua kali dalam selang waktu 5 menit (Dipiro et al., 2015).

Hipertensi bisa terbentuk akibat adanya komplikasi seperti stroke, kelemahan jantung, penyakit jantung koroner (PJK), gangguan ginjal dan lain-lain yang mengakibatkan adanya kelemahan fungsi dari organ vital seperti otak, ginjal dan jantung yang dapat menyebabkan kecacatan atau bahkan kematian. Hipertensi banyak yang menyebut sebagai the silent killer karena merupakan salah satu faktor resiko paling berpengaruh pada penyakit jantung (cardiovascular) (Dipiro et al., 2015).

Pada umumnya prevalensi hipertensi berkisar antara 1,8-28,6\% pada penduduk yang berusia di atas 20 tahun. Namun di beberapa penelitian lain menyebutkan bahwa prevalensi hipertensi berkisar antara 17-22\% (Listyani, 2004). Data (Dinas Kesehatan Provinsi DKI, 2016)Jakarta tahun 2016 menunjukkan bahwa kotamadya Jakarta Timur memiliki jumlah populasi yang hipertensi lebih banyak dibandingkan dengan daerah lainnnya yaitu sebanyak 98422 orang.

Gaya hidup sehat atau kembali ke alam (back to nature) telah menjadi tren baru masyarakat. Konsumsi buah dan sayur setiap hari memberikan banyak manfaat bagi tubuh kita, bukan saja rasanya yang enak tapi buah dan sayur dalam bentuk jus kaya akan antioksidan yang bermanfaat untuk mencegah terjadinya kerusakan sel tubuh akibat oksidan. Selain itu, antioksidan dapat menjadi salah satu usaha dalam mencegah dan mengobati hipertensi. Berbagai buah dan sayuran banyak yang telah diteliti memberikan khasiat antihipertensi. Salah satu produk alami tersebut adalah buah belimbing, mentimun dan lemon yang banyak terdapat di masyarakat. Belimbing merupakan salah satu buah yang banyak dikonsumsi oleh masyarakat serta sudah sejak dulu banyak dimanfaatkan sebagai obat tradisional untuk menurunkan tekanan darah tinggi. Buah ini diketahui mengandung kadar kalium tinggi dan natrium rendah, sehingga sesuai dikonsumsi oleh penderita hipertensi (Wirakusumah, 2004).

Hal ini memacu kami tim dosen Fakultas Farmasi dan Sains Universitas Prof. Dr. HAMKA untuk memberikan edukasi kepada masyarakat sosialisasi kepada masyarakat mengenai penyakit hipertensi dan solusi buah-buah dan sayuran yang dapat dimanfaatkan untuk mengatasi hipertensi. Pada kegiatan PPPM ini kami menjelaskan mengenai penyakit hipertensi baik penyebabnya, faktor pemicunya dan mempraktekkan pembuatan jus nutri si yang bermanfaat untuk penyakit hipertensi pada anggota PKK RT. 014 RW. 05 Perumnas Klender Jakarta Timur. 


\section{MASALAH}

Sampai saat ini, hipertensi masih merupakan tantangan besar di Indonesia. Jumlah penderita penyakit hipertensi yang makin meningkat tiap tahunnya yaitu 17-22\% dan prevalensi tertinggi pada daerah DKI Jakarta ditemukan pada kotamadya Jakarta Timur. Kebiasaan serta pola hidup yang tidak sehat pada masyarakat seperti kebiasaan merokok, konsumsi garam berlebih, konsumsi lemak jenuh, obesitas, kurang aktivitas fisik dan lainlain merupakan faktor pemicu penyakit ini. Pada lingkungan Delima 5 Perumnas Klender banyak ditemukan lansia dengan berbagai penyakit degeneratif terutama hipertensi dan diabetes.

Kegiatan Pengabdian Masyarakat diharapkan dapat menjadi salah satu jalan untuk meningkatkan pemahaman dan pengetahuan tentang manfaat konsumsi buah-buahan dan sayuran segar dalam pengobatan hipertensi. Dengan meningkatnya pemahanam dan pengetahuan kedua hal tersebut, diharapkan mampu menumbuhkan kesadaran dalam konsumsi buah-buahan dan sayuran segar.

\section{METODE PELAKSANAAN}

Metode yang digunakan untuk sosialisasi melalui tatap langsung dan berdiskusi dengan masyarakat disertai dengan praktek langsung pembuatan nutrisi untuk hipertensi dari bahan-bahan buah dan sayur. Adapun tahap-tahap dari kegiatan ini adalah

Pelatihan ini meliputi :

1. Ceramah yaitu pemberian materi mengenai penyakit hipertensi

2. Praktek cara pembuatan jus buah-buahan dan sayuran untuk penderita hipertensi.

3. Evaluasi hasil kegiatan berdasarkan data kesan dan pesan

4. Pembuatan laporan

\section{HASIL DAN PEMBAHASAN}

Edukasi kepada masyarakat dalam mengenal penyakit hipertensi dan cara pengobatan yang tepat pada pasien merupakan salah satu tanggung jawab dari kami sebagai apoteker. Kegiatan ini dilakukan pada tanggal 5 Januari 2019 bersama Ibu-Ibu anggota PKK Delima 5 RT. 014 Perumnas Klender sebanyak 17 orang peserta. Metode yang dilaksanakan pada kegiatan ini adalah edukasi dengan pemberian materi tentang penyakit hipertensi yaitu: penyebab, gejalanya serta cara pengobatan yang tepat bagi pasien. Pada materi mengenai hipertensi ini kami menekankan bagaimana cara untuk mencegah penyakit hipertensi. Sebagaimana diketahui bahwa pencegahan hipertensi dapat 
dilakukan dengan memperbaiki pola hidup yakni dengan olahraga yang teratur dan mengatur pola makan. Pada kegiatan ini kami memberikan solusi mengenai beberapa nutrisi yang dapat digunakan untuk mencegah dan menurunkan tekanan darah pada penderita hipertensi yang dapat dikonsumsi sehari-hari.

Kami memberikan contoh nutrisi dan bentuk produknya yakni jus untuk pasien hipertensi dari sayur dan buah yang mudah didapatkan dan dibuat sendiri oleh warga. Sayur-sayuran dan buah-buahan yang kami gunakan pada jus ini adalah berdasarkan literatur telah terbukti berkhasiat mengurangi penyakit hipertensi. Buah-buahan dan sayursayuran yang kami gunakan adalah belimbing, semangka, lemon, seledri dan mentimun. Kegiatan ini kami lakukan juga demo pembuatan resep jus yang telah kami uji coba takarannya sebelumnya. Antusias dari peserta sangat terlihat saat mengikuti penyuluhan yaitu banyaknya peserta yang bertanya terkait tema yang dijelaskan.

\section{KESIMPULAN}

Kegiatan pengabdian seperti ini sangat diperlukan untuk meningkatkan pemahaman masyarakat dalam mengatasi penyakit hipertensi, pengobatan yang tepat serta nutrisi yang sebaiknya dikonsumsi oleh penderita hipertensi. Dengan dilakukannya kegiatan ini diharapkan dapat meningkatkan kesadaran peserta dalam menjaga kesehatan dan mengetahui nutrisi-nutrisi yang bisa dikonsumsi sehingga membantu program pemerintah dalam mengurangi resiko penyakit hipertensi.

\section{UCAPAN TERIMA KASIH}

Ucapan terima kasih terutama ditujukan kepada LPPM Universitas Muhammadiyah Prof. Dr. Hamka karena telah mendanai program pengabdian masyarakat ini.

\section{DAFTAR PUSTAKA}

Dinas Kesehatan Provinsi DKI. (2016). Dinas Kesehatan Provinsi DKI. 2016. Profil Kesehatan Provinsi DKI Jakarta Tahun 2016. Bidang Perencanaan dan Pembiayaan Dinas Kesehatan Provinsi DKI Jakarta.

Dipiro, J. T., Talbert, R. L., Yee, G. C., Matze, G. R., Wells, B. G., \& Posey, L. M. (2015). Pharmacotherapy handbook. https://doi.org/10.1016/j.jbiomech.2008.06.013

Wirakusumah, E. S. (2004). Buah dan Sayuran untuk Terapi. Jakarta: Penebar Swadaya.

\section{(c) (i)}

(C) 2019 Oleh authors. Lisensi Jurnal Solma, LPPM-Uhamka, Jakarta. Artikel ini bersifat open access yang didistribusikan di bawah syarat dan ketentuan Creative Commons Attribution (CC BY) license. (http://creativecommons.org/licenses/by/4.0/). 